\title{
Drying of Plectranthus amboinicus (lour) spreng leaves by using oven dryer
}

\begin{abstract}
Plectranthus amboinicus (lour) Spreng is the herbal species belongs to the family of Lamiaceae. The leaves of this species contain Thymol which is the main bioactive compound that has anti-inflammatory, antibacterial, antifungal and antioxidant properties. In this study, oven dryer has been chosen due to its easy handling and simple operation. The Plectranthus amboinicus leaves were dried under different temperatures at $50{ }^{\circ} \mathrm{C}, 60^{\circ} \mathrm{C}$, $70{ }^{\circ} \mathrm{C}$ and $80^{\circ} \mathrm{C}$ using oven dryer. Drying took place at constant rate and falling rate period. The moisture ratio data were fitted to six thin layer models chosen from literature. Among these models, Midilli and Kucuk model was found to be the best model to represent the drying behaviour of Plectranthus amboinicus leaves due to the highest value of coefficient of determination $\left(\mathrm{R}^{2}\right)$ and lowest values of root mean square error (RMSE) and reduced Chi$\operatorname{Square}\left(\chi^{2}\right)$. Besides, the effective diffusivities varied from $1.167 \times 10-10$ to $4.451 \times 10-10 \mathrm{~m}^{2} / \mathrm{s}$ which was within the general range for food material. Ultrasound-assisted extraction (UAE) was performed to analyse the quality of dried $P$. amboinicus leaves with ethanol as the solvent using probe sonicator (130 Watts, $20 \mathrm{kHz}$ ) with solid to solvent ratio 1:20 for $30 \mathrm{~min}$. From gas chromatography analysis, leaves dried at $70{ }^{\circ} \mathrm{C}$ gave the highest concentration of thymol compared to drying at other temperatures.
\end{abstract}

Keyword: Plectranthus amboinicus (lour) Spreng; Thymol; Mathematical modeling; Effective moisture diffusivity $\left(\mathrm{D}_{\text {eff }}\right)$; Ultrasound-assisted extraction (UAE) 